\title{
Pelaksanaan Penjahitan dengan Metode Jelujur Pada Laserasi Jalan Lahir Tingkat I Sebagai Upaya Pencegahan Perdarahan Pada Ibu Bersalin
}

\section{Bina Aquari}

Akademi Kebidanan Budi Mulia Palembang

\section{Informasi Artikel :}

Diterima : 10 November 2020

Direvisi : 19 November 2020

Disetujui : 30 November 2020

*Korespondensi Penulis : Binaplb2201@gmail.com

\begin{abstract}
A B S T R A K
Laserasi jalan lahir adalah laserasi yang terjadi biasanya ringan tetapi seringkali juga terjadi laserasi yang luas dan berbahaya, untuk itu setelah persalinan harus di lakukan pemeriksaan vulva dan perineum. Perdarahan dalam keadaan dimana plasenta telah lahir lengkap dan kontraksi rahim baik, dapat di pastikan bahwa perdarahan tersebut berasal dari laserasi jalan lahir maka di lakukan dengan metode jelujur. Di Klinik/BP Anisa Mainan, pada tahun 2017 laserasi tingkat I sebanyak 84 persalinan atau 42,63\% dari 197 persalinan normal. Sedangkan tahun 2018 laserasi tingkat I sebanyak 96 persalinan atau 49,48\% dari 194 persalinan normal dan tahun 2019 masih meningkat yaitu laserasi tingkat I sebanyak 97 persalinan atau 53,00 \% dari 183 persalinan normal. Tujuan untuk mengetahui pelaksanaan penjahitan dengan metode jelujur pada laserasi jalan lahir tingkat I sebagai upaya untuk pencegahan perdarahan pada ibu bersalin di Klinik/BP Anisa Mainan tahun 2020. Penelitian menggunakan metode action research dengan tujuan utama pelaksanaan kegiatan atau tindakan perbaikan sesuatu yang perencanaan, pelaksanaan, dan evaluasinya. Populasi penelitian adalah semua ibu bersalin yang berkunjung di Klinik/BP Anisa Mainan berjumlah 35 responden. Sampel menggunakan accidendal sampling, pengumpulan data dilakukan dengan cara menggunakan cek list dan wawancara yaitu 10 responden. Hasil analisa dalam bentuk narasi di dapatkan 10 responden yang standar pelaksanaan penjahitan metode jelujur pada laserasi jalan lahir tingkat I, dan 8 responden setelah di lakukan penjahitan tidak terjadi perdarahan hanya 2 responden yang mengalami perdarahan akibat kontraksi uterus tidak baik. Berdasarkan hasil penelitian di harapkan bagi pasien setelah di lakukan penjahitan agar bermobilisasi dini dan agar dapat melakukan perawatan luka penjahitan dan bagi petugas kesehatan dapat tetap meningkatkan mutu kerja yang baik.
\end{abstract}

Kata Kunci :Laserasi Jalan Lahir Tingkat I

\section{ABSTRACT}

Birth way laceration is a common laceration usually mild but sometimes it becomes an extensive lacerations and dangerous, so after the delivery vulva and perineum examination must be done. The bleeding in a situation where placenta has delivered and good uterus contraction, it is sure that the bleeding come from birth way laceration then it is done by baste method. In, in 2017 the first level of laceration they were 84 deliveries or 42,63\% from 197 normal delivery. While in 2018 the first level laceration 96 deliveries or 49,48\% from 194 normal delivery and in 2019 increased first level laceration 97 deliveries or 53,00\% from 183 normal deliveries. The purpose is to figure out the stitching implementation with baste method to first level laceration as an effort to prevent postpartum bleeding in Klinik/BP Anisa Mainan 2020. The research used action research method with the main objective the implementation of activity or corrective activity something that planning, implementing and evaluating. The research population all maternity mothers who visited Klinik/BP 
Anisa Mainan 202035 respondents. By using accidental sampling data collection is done by using check list and interview for 10 respondents.The analysis result in a narrative report had 10 respondents with standard implementation stitching with baste method in birth way laceration first level, and 8 respondents had no bleeding after the stitching only 2 respondents had bleeding because of bad uterus contraction. Based on research result it is hoped that patients after stitching to do early mobilization and get stitching wound care and for health worker can continue to improve good work quality.

\section{Keywords $\quad$ : First level laceration birth way}

\section{PENDAHULUAN}

Setiap hari pada tahun 2017 sekitar $810 \mathrm{ibu}$ di dunia meninggal dunia akibat persalinan. 94 persen dari semua kematian ibu terjadi di negara berpenghasilan rendah dan menengah ke bawah. Menurut laporan World Health Organization (WHO), penyebab langsung kematian ibu terjadi saat dan pasca-melahirkan. 75 persen kasus kematian ibu diakibatkan oleh perdarahan, infeksi, atau tekanan darah tinggi saat kehamilan (WHO,2020).

Angka kematian ibu (AKI) menurut Survei Demografi Kesehatan Indonesia (SDKI) pada tahun 2019 masih berkisar 305 per 100.000 kelahiran hidup. Angka itu jauh tertinggal dibandingkan dengan negara ASEAN lain yang berkisar pada 40 sampai 60 per 100.000 kelahiran hidup. Salah satu penyebab utama masih tingginya angka kematian ibu (AKI) di Indonesia yaitu karena perdarahan, baik itu pada masa kehamilan, persalinan maupun pada masa nifas. Perdarahan pascapersalinan merupakan penyebab dari keseluruhan kematian akibat perdarahan (Mayasari, 2011).

Angka kematian ibu (AKI) di Provinsi Sumatera Selatan pada tahun 2008 adalah 79,31 per 100.000 kelahiran hidup, 124 penyebab kematian akibat perdarahan, sedangkan tahun 2009 adalah 150,93 per 100.000 kelahiran hidup, 143 penyebab kematian akibat perdarahan (Dinkes Provinsi Sum-Sel, 2009).

Kematian Ibu di Provinsi Sumatera Selatan tahun 2018 sebanyak 120 orang meningkat dari tahun 2017 sebanyak 107 orang. Penyebab kematian ibu adalah Perdarahan, Hipertensi Dalam Kehamilan (HDK), Infeksi, Gangguan Sistem Peredaran Darah (Jantung, Stroke, dll), Gangguan Metabolik (Diabetes Mellitus, dll), dan lain-lain. Penyebab kematian ibu di Provinsi Sumatera Selatan dapat dilihat pada tabel dibawah ini. (Profil Kesehatan Dinkes Provinsi Sumsel, 2018).
Perdarahan pasca persalinan yang dapat menyebabkan kematian ibu $45 \%$ terjadi pada 24 jam pertama setelah bayi lahir, $68-73 \%$ dalam satu minggu setelah bayi lahir, dan 82-88\% dalam dua minggu setelah bayi lahir. Perdarahan pascapersalinan terdiri dari atonia uteri, laserasi jalan lahir, retensio plasenta, inversi uteri, perdarahan karena gangguan pembekuan darah. Perdarahan dalam keadaan dimana plasenta telah lahir lengkap dan kontraksi rahim baik, dapat di pastikan bahwa perdarahan tersebut berasal dari laserasi jalan lahir (Prawirohardjo, 2008).

Laserasi jalan lahir terdapat tingkat I sampai tingkat IV di mana wewenang seorang bidan pada ibu bersalin yang terdapat laserasi jalan lahir adalah tingkat I dan tingkat II. Bidan harus melakukan penjahitan jelujur pada ibu bersalin yang mengalami laserasi tingkat I atau tingkat II upaya untuk pencegahan perdarahan (Esti, 2010).

Teknik penjahitan laserasi jalan lahir di lakukan pada tingkat I dapat menggunakan dengan metode jelujur tingkat I pada laserasi jalan lahir, Tujuan laserasi untuk menyatukan kembali (mendekatkan) jaringan tubuh, mencegah kehilangan darah yang tidak perlu memastikan hemostasis (Esti, 2010).

Berdasarkan dari data catatan di Klinik/BP Anisa Mainan, angka laserasi tingkat I yang di alami ibu bersalin di Klinik/BP Anisa Mainan mengalami peningkatan selama tiga tahun terakhir, pada tahun 2017 laserasi tingkat I sebanyak 84 persalinan atau 42,63\% dari 197 persalinan normal. Sedangkan tahun 2018 laserasi tingkat I sebanyak 96 persalinan atau 49,48 \% dari 194 persalinan normal dan tahun 2019 masih meningkat yaitu laserasi tingkat I sebanyak 97 persalinan atau 53,00\% dari 183 persalinan normal (Klinik/BP Anisa, 2019).

Dari data diatas maka penulis tertarik untuk meneliti "Pelaksanaan Penjahitan Dengan Metode Jelujur Pada Laserasi Jalan Lahir Tingkat I Sebagai Upaya Untuk Pencegahan Perdarahan Pada Ibu Bersalin Di Klinik/BP Anisa Mainan Tahun 2020". 


\section{METODE PENELITIAN}

Desain penelitian action research adalah untuk mencari suatu dasar pengetahui praktik guna memperbaiki suatu situasi atau keadaan kesehatan masyarakat, yang di lakukan secara terbatas di mana pemecahan masalah perlu di lakukan dan hasilnya di perlukan untuk memperbaiki suatu keadaan. (Notoadmojo, 2002). Populasi adalah keseluruhan objek penelitian atau objek yang di teliti, (Notoatmodjo, 2005), Populasi dalam penelitian ini adalah semua ibu bersalin yang berkunjung di Klinik/BP Anisa pada tanggal 20 Febuari sampai dengan 24 Maret tahun 2020, Sampel penelitian adalah sebagian yang diambil dari keseluruhan objek yang diteliti dan dianggap mewakili populasi ( Notoatmodjo,2005), dari ibu yang mengalami laserasi jalan lahir tingkat I yang bersalin di Klinik/BP Anisa pada tanggal 20 Febuari sampai dengan 24 Maret tahun 2020, accidental sampling yaitu penelitian yang dilakukan dengan mengambil kasus atau responden yang kebetulan ada atau tersedia, dengan jumlah sample 35 orang.

Analisa data adalah mendeskrisikan dalam bentuk narasi yang berupa observasi dan evaluasi atau pemantauan dalam setiap pelaksanaan tindakan pada penelitian pelaksanaan penjahitan dengan metode jelujur tingkat I pada laserasi jalan lahir dengan cara periksa tempat laserasi jalan lahir tingkat I yaitu mukosa vagina, komisura posterior, kulit perineum, dan alat heacting set yang sudah dapat di gunakan, memberikan suntikan anestesi agar ibu tidak merasa sakit pada saat di hetting dengan cara menanyakan ibu setelah di lakukan penjahitan pertama, kemudian lakukan penjahitan metode jelujur gunanya peyatuan laserasi jalan lahir dan evaluasi perdarahan tidak terjadi perdarahan pada laserasi jalan lahir. Di teliti menggunakan cek list dengan tujuan mengobservasi, mengetahui keadaan, untuk mencegah perdarahan pada laserasi jalan lahir tingkat I.

\section{HASIL PENELITIAN}

\section{Pelaksanaan penjahitan metode jelujur pada laserasi jalan lahir tingkat I}

Berdasarkan penelitian pada responden

10 postpartum di dapatkan standar pelaksanaan penjahitan metode jelujur pada laserasi jalan lahir tingkat I, persiapkan alat heacting set, pinset cerugi, nald foeder, cat gut keromik 3-0, bengkok, gunting udah di siapkan terlebih dahulu, setelah plasenta lahir, memberitahukan kepada ibu bahwa akan di periksa tempat jalan lahir. Maka di lakukan menggunakan kassa steril dengan cara menekan pada bagian jalan lahir dan melihat ada laserasi jalan lahir di bagian mukosa vagina, komisura posterior, kulit perineum setelah mengetahui tempat laserasi, memberitahukan ibu bahwa terdapat laserasi jalan lahir harus di lakukan penjahitan, ibu setuju untuk di lakukan penjahitan, sebelum di lakukan penjahitan ambil tampon untuk mempermudah kerja, memasang lampu kemudian duduk dengan posisi yang paling nyaman dan pastikan semuanya telah siap sehingga tidak terganggu saat melakukan penjahitan, memeriksa uterus untuk memastikan uterus berkontraksi dengan baik, kaji ulang tempat penjahitan dengan menggunakan kassa steril berikan dukungan

emosional seperti pasien jangan terlalu tegang dan harus rileks, pasang perlak dan pengalas di pasang di bawah bokong, menanyakan tidak ada alergi terhadap lidocain atau obat-obatan sejenis masukkan jarum pada ujung atau pojok laserasi dan dorong masuk sepanjang luka mengikuti garis tempat jarum jahitnya akan masuk atau keluar, aspirasikan dan kemudian suntikan sekitar $1 \mathrm{ml}$ lidocain di bawah mukosa vagina, dan di bawah kulit, setelah di suntikan bagian laserasi sambil kita sentuh dan menayakan kepada ibu apakah terasa sakit atau tidak jika ibu merasa tidak sakit berarti suntikan lidocain telah beraksi lalu melakukan, penjahitan metode jelujur ambil bagian puncak mukosa vagina dengan menggunakan cat gut kromik, lalu menekan kembali bagi yang luka dengan kassa, mulai dari sekitar $1 \mathrm{~cm}$ di atas puncak luka jahit bagian dalam vagina dengan cara jelujur dimulai dari komisura posterior dan selesai sampai pada batas vagina, lalu menekan kembali bagi yang luka dengan kassa kemudian jahit lapisan bagian kulit perineum jika terasa sakit suruh ibu tarik nafas, akhiri dengan simpul mati pada bagian dalam vagina, untuk membuat simpul mati benarbenar kuat, potong kedua ujung benang, dan hanya disisakan $1 \mathrm{~cm}$, setelah selesai melakukan penjahitan metode jelujur, ambil tampon secara berlahan sambil bilang kepada ibu supaya tarik napas, melakukan eksporasi dalam vagina apakah ada sisa plasenta, lakukan colok rectal dengan cara tangan kelingking masuk ke dalam anus, dan pastikan laserasi sudah terjahit semua dan jahitan tidak ada bagian rectum terjahit lalu cuci tangan dan membersihkan bagian vulva ibu dengan handuk yang basah dan bersih, ambil kassa 
Jurnal Kebidanan :Jurnal Medical Science Ilmu Kesehatan Akademi Kebidanan Budi Mulia Palembang Volume.10 No.2, Desember 2020

yang steril yang sudah di kasih behtadine balutkan pada tempat yang luka, memberitahukan kepada ibu jika ada benang jangan di cabut dan jangan takut untuk melakukan mobilisasi dan mengajari ibu jika habis BAK, BAB atau mandi ganti kassa yang steril yang di kasih behtadine pada bagian luka, membantu ibu memasangkan softek, jika ibu merasa darah yang keluar terlalu deras segera beritahu bidan. dan yang tidak menurut standar pelaksanaan penjahitan metode julujur sebanyak.

2. Jumlah perdarahan setelah di lakukan penjahitan metode jelujur pada laserasi jalan lahir tingkat I

Evaluasi perdarahan setelah di lakukan penjahitan metode jelujur pada laserasi jalan lahir tingkat I dengan menggunakan bengok atau melihat ukuran softek yang di pakai ibu seperti :

Tabel 1 Observasi 2 Jam Postpartum Pada 15 Menit Pertama Selama 1 Jam

\begin{tabular}{|c|c|c|c|c|c|c|}
\hline \multirow{2}{*}{$\begin{array}{l}\mathbf{N} \\
\mathbf{o}\end{array}$} & \multirow{2}{*}{ Nama } & \multicolumn{4}{|c|}{1 jam pertama } & \multirow{2}{*}{$\begin{array}{c}\text { Jumlah } \\
\text { perdarahan }\end{array}$} \\
\hline & & $\begin{array}{c}15 \\
\text { menit }\end{array}$ & $\begin{array}{c}15 \\
\text { menit }\end{array}$ & $\begin{array}{c}15 \\
\text { menit }\end{array}$ & $\begin{array}{c}15 \\
\text { menit }\end{array}$ & \\
\hline 1 & Ny. S & $15 \mathrm{cc}$ & $15 \mathrm{cc}$ & $15 \mathrm{cc}$ & $10 \mathrm{cc}$ & $55 \mathrm{cc}$ \\
\hline 2. & Ny.Y & $15 \mathrm{cc}$ & $15 \mathrm{cc}$ & $15 \mathrm{cc}$ & $10 \mathrm{cc}$ & $55 \mathrm{cc}$ \\
\hline 3. & Ny.S & $15 \mathrm{cc}$ & $15 \mathrm{cc}$ & $15 \mathrm{cc}$ & $15 \mathrm{cc}$ & $60 \mathrm{cc}$ \\
\hline 4. & Ny.H & $15 \mathrm{cc}$ & $10 \mathrm{cc}$ & $10 \mathrm{cc}$ & $10 \mathrm{cc}$ & $45 c c$ \\
\hline 5. & Ny.R & $10 \mathrm{cc}$ & $15 \mathrm{cc}$ & $15 \mathrm{cc}$ & $15 \mathrm{cc}$ & $55 \mathrm{cc}$ \\
\hline 6. & Ny.N & $15 \mathrm{cc}$ & $15 \mathrm{cc}$ & $15 \mathrm{cc}$ & $15 \mathrm{cc}$ & $60 \mathrm{cc}$ \\
\hline 7. & Ny.S & $10 \mathrm{cc}$ & $15 \mathrm{cc}$ & $15 \mathrm{cc}$ & $10 \mathrm{cc}$ & $40 \mathrm{cc}$ \\
\hline 8. & Ny.A & $15 \mathrm{cc}$ & $15 \mathrm{cc}$ & $15 \mathrm{cc}$ & $15 \mathrm{cc}$ & $60 \mathrm{cc}$ \\
\hline 9. & Ny.R & $15 \mathrm{cc}$ & $15 \mathrm{cc}$ & $20 \mathrm{cc}$ & $15 \mathrm{cc}$ & $65 \mathrm{cc}$ \\
\hline 10 & Ny.F & $15 \mathrm{cc}$ & $15 \mathrm{cc}$ & $15 \mathrm{cc}$ & $15 \mathrm{cc}$ & $60 \mathrm{cc}$ \\
\hline
\end{tabular}

Tabel 2 Observasi 2 Jam Postpartum Pada 30 Menit Kedua Selama 1 Jam

\begin{tabular}{|c|c|c|c|c|c|}
\hline \multirow{2}{*}{$\begin{array}{l}\mathbf{N} \\
\mathbf{0}\end{array}$} & \multirow{2}{*}{ Nama } & \multirow{2}{*}{ Lochea } & \multicolumn{2}{|c|}{$\begin{array}{c}1 \text { jam } \\
\text { pertama }\end{array}$} & \multirow{2}{*}{$\begin{array}{c}\text { Jumlah } \\
\text { perdarahan }\end{array}$} \\
\hline & & & $\begin{array}{c}15 \\
\text { menit }\end{array}$ & $\begin{array}{c}15 \\
\text { menit }\end{array}$ & \\
\hline 1 & Ny.S & Rubra & $60 \mathrm{cc}$ & $60 \mathrm{cc}$ & $120 \mathrm{cc}$ \\
\hline 2 & Ny.Y & Rubra & $60 \mathrm{cc}$ & $30 \mathrm{cc}$ & $90 \mathrm{cc}$ \\
\hline 3 & Ny.S & Rubra & $40 \mathrm{cc}$ & $10 \mathrm{cc}$ & $50 \mathrm{cc}$ \\
\hline 4 & Ny.H & Rubra & $30 \mathrm{cc}$ & $15 \mathrm{cc}$ & $45 \mathrm{cc}$ \\
\hline 5 & Ny.R & Rubra & $30 \mathrm{cc}$ & $30 \mathrm{cc}$ & $60 \mathrm{cc}$ \\
\hline 6 & Ny.N & Rubra & $150 \mathrm{cc}$ & $100 \mathrm{cc}$ & $250 \mathrm{cc}$ \\
\hline 7 & Ny.S & Rubra & $30 \mathrm{cc}$ & $50 \mathrm{cc}$ & $80 \mathrm{cc}$ \\
\hline 8 & Ny.A & Rubra & $150 \mathrm{cc}$ & $50 \mathrm{cc}$ & $200 \mathrm{cc}$ \\
\hline 9 & Ny.R & Rubra & $60 \mathrm{cc}$ & $40 \mathrm{cc}$ & $100 \mathrm{cc}$ \\
\hline 10 & Ny.F & Rubra & $50 \mathrm{cc}$ & $30 \mathrm{cc}$ & $80 \mathrm{cc}$ \\
\hline
\end{tabular}

Tabel 3 Observasi 8 Jam Setelah Persalinan

\begin{tabular}{llcl}
\hline No & Nama & Jumlah perdarahan 8 jam & Lochea \\
\hline 1. & Ny.S & $100 c c$ & Rubra \\
\hline 2. & Ny.Y & $30 c c$ & Rubra \\
\hline 3. & Ny.S & $30 c c$ & Rubra \\
\hline 4. & Ny.H & $30 c c$ & Rubra \\
\hline 5. & Ny.R & $30 c c$ & Rubra \\
\hline 6. & Ny.N & $100 c c$ & Rubra \\
\hline 7. & Ny.S & $30 c c$ & Rubra \\
\hline 8. & Ny.A & $80 c c$ & Rubra \\
\hline 9. & Ny.R & $80 c c$ & Rubra \\
\hline 10. & Ny.F & $50 c c$ & Rubra \\
\hline
\end{tabular}

Tabel 4 Observasi Hari Kedua

\begin{tabular}{llll}
\hline No & Nama & Jumlah perdarahan & Lochea \\
\hline 1. & Ny.S & $30 c c$ & Rubra \\
\hline 2. & Ny.Y & $30 c c$ & Rubra \\
\hline 3. & Ny.S & $30 c c$ & Rubra \\
\hline 4. & Ny.H & $20 c c$ & Rubra \\
\hline 5. & Ny.R & $30 c c$ & Rubra \\
\hline 6. & Ny.N & $30 c c$ & Rubra \\
\hline 7. & Ny.S & $30 c c$ & Rubra \\
\hline 8. & Ny.A & $60 c c$ & Rubra \\
\hline 9. & Ny.R & $30 c c$ & Rubra \\
\hline 10. & Ny.F & $30 c c$ & Rubra \\
\hline
\end{tabular}

Tabel 5 Observasi Kunjungan Ulang

\begin{tabular}{lllcc}
\hline No & Nama & Anak & $\begin{array}{c}\text { Tanggal } \\
\text { kunjungan } \\
\text { ulang }\end{array}$ & $\begin{array}{c}\text { Ganti } \\
\text { pembalut }\end{array}$ \\
\hline 1. & Ny.S & G1P0A0 & $07-03-2012$ & $2 \mathrm{x}$ \\
\hline 2. & Ny.Y & G2P1A0 & $20-03-2012$ & $2 \mathrm{x}$ \\
\hline 3. & Ny.S & G3P2A0 & $21-03-2012$ & $2 \mathrm{x}$ \\
\hline 4. & Ny.H & G1P0A0 & $24-03-2012$ & $1 \mathrm{x}$ \\
\hline 5. & Ny.R & G2P1A0 & $27-03-2012$ & $3 \mathrm{x}$ \\
\hline 6. & Ny.N & G2P1A0 & $28-03-2012$ & $1 \mathrm{x}$ \\
\hline 7. & Ny.S & G1P0A0 & $29-03-2012$ & $1 \mathrm{x}$ \\
\hline 8. & Ny.A & G1P0A0 & $04-04-2012$ & $1 \mathrm{x}$ \\
\hline 9. & Ny.R & G1P0A0 & $05-04-2012$ & $2 \mathrm{x}$ \\
\hline 10. & Ny.F & G1P0A0 & $06-04-2012$ & $3 \mathrm{x}$ \\
\hline
\end{tabular}

\section{PEMBAHASAN}

\section{Standar Pelaksanaan}

Dari hasil penelitian, ibu yang mengalami laserasi jalan lahir tingkat I yang menjadi responden 10 orang. Berdasarkan hasil penelitian standar pelaksanaan penjahitan metode jelujur sebanyak 10 orang. Hasil dari seluruh penelitian terdapat 10 respoden ibu yang mengalami laserasi jalan lahir tingkat I dari 35 responden ibu yang bersalin Di Klinik/BP Anisa Mainan Sembawa Banyuasin.

Dari hasil penelitian pelaksanaan penjahitan metode jelujur pada laserasi jalan lahir tingkat I dari 10 responden sesuai dengan standar pelaksanaan berdasarkan protap yang ada di klinik tersebut dengan baik. Menurut asumsi penulis dari hasil penelitian standar pelaksanaan tersebut berdasarkan urutan protap yang ada di 
Jurnal Kebidanan :Jurnal Medical Science Ilmu Kesehatan Akademi Kebidanan Budi Mulia Palembang Volume.10 No.2, Desember 2020

klinik dan sebelumnya sudah di latih terlebih dahulu pada pelaksanaan penjahitan metode jelujur.

\section{Jumlah Perdarahan}

Dari hasil penelitian yang di dapatkan dengan 10 responden bahwa 8 responden yang di lakukan laserasi jalan lahir tingkat I tidak mengalami perdarahan setelah di lakukan penjahitan metode jelujur, sedangkan 2 responden yang mengalami perdarahan akibat kontraksi uterus tidak baik dari hasil yang di teliti.

Perdarahan pascapersalinan adalah perdarahan yang melebihi $500 \mathrm{ml}$ setelah bayi lahir (Saifuddin, 2002). Perdarahan pascapersalinan dapat terjadi 24 jam setelah kelahiran dan biasanya melibatkan kehilangan banyak darah melalui saluran genital (Vicky, 2006).

Dari hasil penelitian, setelah di lakukan penjahitan metode jelujur dan mengetahui jumlah perdarahan masih ada megalami perdarahan sebanyak 2 responden kontraksi uterus yang tidak baik bukan karena laserasi jalan lahir. Menurut asumsi penulis dari hasil penelitian yang di lakukan jumlah perdarahan sebaiknya ibu melakukan mobilisasi dini dan perawatan luka dengan baik.

\section{KESIMPULAN DAN SARAN \\ Kesimpulan}

Berdasarkan hasil penelitian yang di laksanakan di Klinik/BP Anisa Mainan pelaksanaan penjahitan metode jelujur pada laserasi jalan lahir tingkat I pada ibu bersalin, maka dapat di tarik kesimpulan sebagai berikut: Dari standar pelaksanaan penjahitan metode jelujur, di dapat responden sebanyak 10 orang sesuai dengan standar pelaksanaan metode jelujur pada laserasi jalan lahir tingkat I menggunakan protap yang ada di bidan tersebut. Jumlah perdarahan hasil penelitian yang di dapatkan dengan 10 responden bahwa 8 responden yang di lakukan laserasi jalan lahir tingkat I tidak mengalami perdarahan setelah di lakukan penjahitan metode jelujur, sedangkan 2 responden mengalami perdarahan bukan karena laserasi jalan lahir tetapi melainkan kontraksi uterus yang tidak baik.

\section{Saran}

\section{Bagi Klinik/BP Anisa}

$$
\text { Bagi Klinik/BP Anisa tetap }
$$
meningkatkan kualitas dan motivasi kerja.

\section{Bagi Pasien}

Bagi pasien setelah di lakukan penjahitan metode jelujur pada laserasi jalan lahir tingkat I agar bisa rmobilisasi dini dan dapat melakukan perawatan penjahitan pada luka.

\section{Bagi Pendidikan}

Penelitian ini diharapkan dapat menjadi bahan referensi buku-buku dan merupakan informasi lengkap yang bermanfaat untuk mahasiswi Akbid Budi Mulia Palembang.

\section{DAFTAR PUSTAKA}

Ai Yeyeh, Lia. (2010). Asuhan Kebidan Patologi. Trans Info Media. Jakarta.

Chapman, Vicky. (2006). Asuhan Kebidanan Persalinan dan kelahiran. EGC. Jakarta

Data Dinas Kesehatan, (2018). Profil Kesehatan Dinkes Provinsi Sumatera Selatan

NPKKR, (2008). Asuhan Persalinan Normal. Jakarta

Liu, david T. Y. (2008). Manual Plasenta. Edisi 3 EGC. Jakarta

Mitayani, (2009). Asuhan Keperawatan Maternitas. Salemba Medika. Jakarta

Nining, Wiyati, (2009). Asuhan Kebidanan Pada Ibu Bersalin. Penerbit Fitramaya Yogyakarta.

Notoatmodjo, Soekidjo, (2005). Metodelogi Penelitian Kesehatan. Rineka Cipta. Jakarta

Notoatmojo, Soekidjo. (2010). Metodelogi Penelitian. Rineka Cipta. Jakarta

Nursalam, (2003), Konsep dan Penerapan Metodelogi Penelitian Ilmu Keperawatan. Rineka Cipta. Jakarta

Rohani, Marisah, (2010). Asuhan Kebidanan Pada Masa Persalinan. Salemba Medika. Jakarta

Sarwono, Prawirohardjo. (2008). Ilmu Kebidanan. YBPSP. Jakarta

Sulistyawati, Ari, dkk. (2009). Asuhan Kebidanan Pada Ibu Bersalin. Medika Salemba. Jakarta 
Jurnal Kebidanan :Jurnal Medical Science Ilmu Kesehatan Akademi Kebidanan Budi Mulia Palembang Volume.10 No.2, Desember 2020

Sumarah, (2009). Buku Asuhan Perawatan Ibu Bersalin (Asuhan Kebidanan Pada Ibu Bersalin). Penerbit Fitramaya. Jogyakarta

Syaifuddin, Abdul Bari. (2002). Buku Panduan Praktis Pelayanan Kesehatan Maternal dan Neonatal. YBPSP. Jakarta

Syaifuddin, Abdul Bari. (2006). Buku Acuan Nasional Pelayanan Kesehatan Maternal Dan Neonatal. YSPSP. Jakarta

Klinik/BP Anisa, (2020). Profil Data Klinik/BP Anisa. Mainan, Sembawa, Banyuasinory.usu.ac.id, 2010. 
